\title{
Regulation of scar formation by vascular endothelial growth factor
}

\author{
Traci A Wilgus ${ }^{1,5}$, Ahalia M Ferreira ${ }^{2}$, Tatiana M Oberyszyn ${ }^{3}$, Valerie K Bergdall ${ }^{4}$ and Luisa A DiPietro ${ }^{1}$
}

Vascular endothelial growth factor (VEGF-A) is known for its effects on endothelial cells and as a positive mediator of angiogenesis. VEGF is thought to promote repair of cutaneous wounds due to its proangiogenic properties, but its ability to regulate other aspects of wound repair, such as the generation of scar tissue, has not been studied well. We examined the role of VEGF in scar tissue production using models of scarless and fibrotic repair. Scarless fetal wounds had lower levels of VEGF and were less vascular than fibrotic fetal wounds, and the scarless phenotype could be converted to a scarforming phenotype by adding exogenous VEGF. Similarly, neutralization of VEGF reduced vascularity and decreased scar formation in adult wounds. These results show that VEGF levels have a strong influence on scar tissue formation. Our data suggest that VEGF may not simply function as a mediator of wound angiogenesis, but instead may play a more diverse role in the wound repair process.

Laboratory Investigation (2008) 88, 579-590; doi:10.1038/labinvest.2008.36; published online 21 April 2008

KEYWORDS: angiogenesis; fibrosis; skin; wound healing; fetal

Wound healing in adult skin is comprised of several overlapping phases, and includes the induction of acute inflammation, the rapid proliferation of reparative cells, and the formation of a permanent scar. ${ }^{1,2}$ Aside from the psychological and social detriments associated with prominent scars, there are many other problems with excessive scar tissue, including restricted joint mobility, impaired growth, and loss of organ function. ${ }^{3,4}$ Whereas adult skin always heals with a scar, the same is not true for developing embryonic skin. Throughout the first and second trimesters of development, fetal skin heals scarlessly. ${ }^{5}$ At this stage, skin heals by regeneration, which occurs very rapidly and without significant inflammation or scarring. ${ }^{6}$ However, during the third trimester, the healing outcome in the skin is fibrotic, and the skin heals like that of an adult: slower, with significant inflammation, and with a scar. During development of mouse skin, the transition from scarless to fibrotic healing occurs after embryonic day 16 (E16). ${ }^{7-9}$ Thus, murine fetal skin can be wounded in utero at E15 and E18 to investigate scarless and fibrotic fetal healing, respectively. ${ }^{10}$
Angiogenesis, the process of new blood vessel growth, is a key element of the proliferative phase of healing. Most studies suggest that neovascularization is important for healing, supplying oxygen and nutrients to support the rapid growth of the cells mediating repair. Wound angiogenesis is controlled to a large degree by levels of the proangiogenic factor vascular endothelial growth factor-A (VEGF). ${ }^{11}$ VEGF is a 40 - to $45-\mathrm{kDa}$ homodimeric glycoprotein that was initially found to regulate the permeability of blood vessels. ${ }^{12}$ Subsequent studies also found that it was a potent mitogen for vascular endothelial cells and could induce angiogenesis in vivo. ${ }^{13,14}$ VEGF binds two high-affinity tyrosine kinase receptors to exert its effects on vascular endothelial cells, vascular endothelial growth factor receptor-1 (VEGFR-1) (flt-1) and VEGFR-2 (flk-1 or KDR). ${ }^{15}$ Signaling through these receptors regulates proliferation, migration, and spread of endothelial cells required for sprouting of new vessels. ${ }^{15}$ Keratinocytes in the epidermis are thought to be the main source of VEGF during wound healing, ${ }^{16}$ but VEGF is also produced by dermal fibroblasts and macrophages in response to injury. ${ }^{11,16}$

\footnotetext{
'Department of Periodontics, Center for Wound Healing and Tissue Regeneration, University of Illinois at Chicago, Chicago, IL, USA; ${ }^{2}$ Department of Molecular Biology, Loyola University Medical Center, Maywood, IL, USA; ${ }^{3}$ Department of Pathology, The Ohio State University, Columbus, OH, USA and ${ }^{4}$ Department of Veterinary Preventive Medicine, University Laboratory Animal Resources, The Ohio State University, Columbus, OH, USA

Correspondence: Dr LA DiPietro, DDS, PhD, Department of Periodontics, Center for Wound Healing and Tissue Regeneration, University of Illinois at Chicago, 801 South Paulina Street, Room 458, MC 859, Chicago, IL 60612, USA.

E-mail: Idipiet@uic.edu

${ }^{5}$ Current address: Department of Pathology, The Ohio State University, 129 Hamilton Hall, 1645 Neil Avenue, Columbus, OH 43210, USA Grant support: These studies were supported by National Institutes of Health Grants GM55238 (LAD), GM50875 (LAD), and GM72196 (TAW), and a Wound Healing Foundation-3M Fellowship (TAW).
} 
Although the majority of studies examining the function of angiogenesis in wound healing have focused on its overall effect on wound closure or reepithelialization, some suggest that angiogenesis may also impact repair in the dermis. Taken together with the fact that angiogenesis immediately precedes scar tissue formation in adult wounds, we speculated that there is a coupled regulation of these two events. To examine this linkage, fetal and adult wound healing models were used to determine the role of VEGF in the production of scar tissue.

\section{MATERIALS AND METHODS Animal Experiments}

All animal experiments were approved by the appropriate Institutional Animal Care and Use Committee prior to start of experiments.

\section{Fetal wound healing experiments}

A murine model of scarless fetal repair was used to assess the effects of VEGF on scar formation. Female and male FVB mice (Taconic, Germantown, NY, USA) were mated and surgery was performed on the pregnant female 15 or 18 days after the detection of a vaginal plug, designated as day 0 . The E15 and E18 day time points represent ages at which scarless or fibrotic fetal healing take place, respectively. After preparation of the abdomen for aseptic surgery, a midline laparotomy was performed under isoflurane (Abbott Laboratories, Abbott Park, IL, USA) anesthesia. Incisions were made in the uterine wall and amniotic sac overlying each fetus, and a full-thickness incisional wound, approximately $2 \mathrm{~mm}$ in length, was made on the dorsum of the fetus using microsurgical scissors. A 1- $\mu \mathrm{l}$ volume of India ink (Fisher Scientific, Pittsburgh, PA, USA) diluted to $10 \%$ in sterile PBS (Invitrogen Corporation, Carlsbad, CA, USA) was injected subcutaneously into the wound site. Injection of India ink allows visualization of the area after healing has occurred. ${ }^{9}$ To assess the effects of VEGF on scarless repair, some E15 wounds were injected with the India ink solution containing $0.1 \mu \mathrm{g}$ recombinant murine $\mathrm{VEGF}_{164}$ (R\&D Systems, Minneapolis, MN, USA). After the wound was made and injected with ink or ink plus VEGF, the uterine incision was closed using 7-0 nylon suture. After approximately four fetuses were wounded in this manner, the muscle and skin layers of the pregnant mouse were sutured closed. One dose of xylazine $(3 \mathrm{mg} / \mathrm{kg}$; Phoenix Scientific, St Joseph, MO, USA) was given subcutaneously for sedation and analgesia. Wounds were harvested at various time points post-wounding along with age-matched unwounded skin. The tissue was frozen in TBS tissue-freezing media (Triangle Biomedical Sciences, Durham, NC, USA) for immunohistochemistry, fixed in 10\% buffered formalin (Fischer Scientific, Pittsburgh, PA, USA) for histology, or snap frozen for protein analysis.

\section{Adult wound healing experiments}

Female FVB mice (8 weeks old; Taconic) were used to examine the effects of VEGF neutralization on scar formation. Four hours prior to wounding, mice received an intraperitoneal injection of $50 \mu \mathrm{g}$ of neutralizing anti-VEGF antibodies (R\&D Systems) or normal goat IgG (R\&D Systems) that had been dissolved in sterile saline (Abbott Laboratories). Mice received additional injections on 2, 5, 8, and 11 days post-wounding. A similar protocol has previously been shown to inhibit angiogenesis associated with hair growth. ${ }^{17}$ Under isoflurane (Abbott Laboratories) anesthesia, the dorsum of each mouse was shaved and wiped with 70\% isopropyl alcohol. A 3-cm, full-thickness linear incisional wound was made to the right of the spine on each mouse. The wounds were closed with three stainless steel staples (Fisher Scientific). The staples were removed 5 days after the wounds were made. Mice were killed and wound or scar tissue samples were harvested $24 \mathrm{~h}$ or 14 days postwounding. Samples were fixed for histology or electron microscopy or frozen in TBS tissue-freezing media (Triangle Biomedical Sciences) for immunohistochemistry.

\section{Analysis of Blood Vessel Density}

Immunohistochemical staining for the endothelial cell marker PECAM-1 (CD-31) was used to identify blood vessels $10-\mu \mathrm{m}$ cryosections of wounds or unwounded skin. Sections were thawed and fixed in acetone for $15 \mathrm{~min}$. After three washes in PBS, pH 7.4, sections were treated with $0.3 \% \mathrm{H}_{2} \mathrm{O}_{2}$ in methanol for $30 \mathrm{~min}$ to quench endogenous peroxidase activity. The slides were washed in PBS and blocked with normal rabbit serum (1:10; Sigma Chemical Company, St Louis, MO, USA) in PBS for $30 \mathrm{~min}$. Sections were incubated with $1.0 \mu \mathrm{g} / \mathrm{ml}$ of MEC13.3 rat anti-mouse PECAM-1 antibody (anti-CD31; BD Pharmingen, San Diego, CA, USA) in PBS. After a 30-min incubation with PECAM-1 primary antibody, the slides were washed in PBS. Sections were then incubated for $30 \mathrm{~min}$ with $13.3 \mu \mathrm{g} / \mathrm{ml}$ of mouse adsorbed biotinylated rabbit anti-rat IgG antibody (Vector Laboratories, Burlingame, CA, USA). After washes in PBS, all slides were incubated with avidin-biotin-horseradish peroxidase complex (ABC-HRP) (Vector Laboratories) for $30 \mathrm{~min}$, washed, and incubated with the HRP substrate 3,3'-diaminobenzidine (DAB; Kirkegaard and Perry Laboratories, Gaithersburg, MD, USA) for $10 \mathrm{~min}$. After counterstaining with hematoxylin-2 (Richard Allen Scientific), the sections were dehydrated in alcohols and cleared in xylene (Richard Allen Scientific), before coverslips were applied with Cytoseal 280 (Stephens Scientific, Kalamazoo, MI, USA).

PECAM-stained wound sections were used to determine the density of blood vessels within wounds or unwounded skin as outlined previously. ${ }^{18}$ Briefly, images of stained sections were captured using Scion Image software (Scion Corporation, Frederick, MD, USA). The total dermal area to be analyzed was outlined using a freehand drawing tool and measured, and PECAM-positive area was also determined. 
Using these measurements, the percentage of PECAMpositive vessels per total area analyzed (blood vessel density) was calculated.

\section{Detection of Fibroblasts and Myofibroblasts}

Immunohistochemical staining for vimentin and $\alpha$-smoothmuscle actin ( $\alpha$-SMA) was used to identify fibroblasts and myofibroblasts, respectively. Briefly, $5-\mu \mathrm{m}$ paraffin sections were deparaffinized and rehydrated. For vimentin staining, sections were blocked with $10 \%$ normal goat serum (Vector Laboratories) for $30 \mathrm{~min}$, followed by incubation with rabbit anti-vimentin polyclonal antibody (1:200 dilution in serum) for $1 \mathrm{~h}$. After washing in PBS, the sections were incubated with biotinylated goat anti-rabbit antibodies (1:200 dilution in serum; Vector Laboratories) for $30 \mathrm{~min}$. For $\alpha$-SMA detection, staining was performed using the mouse-onmouse (M.O.M.) kit (Vector Laboratories) as instructed by the manufacturer, with mouse monoclonal anti- $\alpha$-SMA antibody (Sigma-Aldrich, St Louis, MO, USA; 30-min incubation). After washes in PBS, all slides were incubated with ABC-HRP (Vector Laboratories) for $30 \mathrm{~min}$, washed, and incubated with the HRP substrate DAB (Kirkegaard and Perry Laboratories). After counterstaining with hematoxylin-2 (Richard Allen Scientific), the sections were dehydrated in varying concentrations of alcohol and cleared in xylene (Richard Allen Scientific), before coverslips were applied with Cytoseal 280 (Stephens Scientific). Scion Image software (Scion Corporation) was used to determine the density of vimentin- or $\alpha$-SMA-positive staining in the sections. The total dermal area (wound bed/scar) to be analyzed was outlined using a freehand drawing tool and measured, and the percentage of positive staining per total area analyzed was determined.

\section{Protein Isolation and ELISA Analysis}

Wounds harvested 12 and $24 \mathrm{~h}$, and 3, 5, and 7 days postwounding from E15 or E18 fetuses and unwounded skin were homogenized in protease inhibitor buffer (PBS containing complete protease inhibitor cocktail tablet; Roche Diagnostics, Mannheim, Germany), sonicated, and centrifuged at 10000 r.p.m. for $10 \mathrm{~min}$. Supernatants were used to analyze VEGF levels by ELISA, as directed by the manufacturer (R\&D Systems). VEGF levels in picograms were normalized to total protein concentrations as determined by the Bio-Rad Protein Assay (Bio-Rad, Hercules, CA, USA).

\section{Measurement of Scar Width}

Samples were fixed in 10\% buffered formalin (Fisher Scientific), processed, and embedded in paraffin. Paraffin sections were subjected to Masson's trichrome staining as previously described. ${ }^{19}$ The width of each scar was measured using a stage micrometer to analyze differences in scar size.

\section{Electron Microscopy}

For ultrastructural collagen analysis, normal skin and scars from mice injected with IgG or anti-VEGF antibodies were fixed in $4 \%$ glutaraldehyde. After rinsing with $0.1 \mathrm{~mol} / \mathrm{l}$ sodium cacodylate buffer, samples were post-fixed in $1 \%$ osmium tetroxide, dehydrated in graded alcohols, and embedded in Spurr's epoxy resin (Electron Microscopy Sciences, Fort Washington, PA, USA). Ultrathin sections $(80 \mathrm{~nm})$ were collected on grids, stained with uracyl acetate and lead citrate, and examined using a Hitachi H-600 (75 kv) transmission electron microscope (TEM). TEM images of collagen fibril cross-sections were taken at a magnification of $\times 30000$ and the photographic negatives were scanned into Adobe Photoshop (Adobe Systems Incorporated, San Jose, CA, USA). Fibril diameters were measured using Scion Image (Scion Corporation) and histograms were produced using GraphPad Prism (GraphPad Software Inc., San Diego, CA, USA). Collagen fibril diameter measurements have been used previously to evaluate the degree of cutaneous fibrosis. ${ }^{20-22}$ Three normal skin samples and six scar samples from each treatment group, all from different mice, were used for analysis. Each micrograph was divided into four parts for analysis and fibrils from four micrographs per sample were measured. A total of $4800-8000$ fibrils per group were analyzed.

\section{Analysis of Inflammation}

Immunohistochemical staining for neutrophils (Ly-6G) and macrophages (MOMA-2) was performed as described above for PECAM, with the following modifications: Ly-6G conditions (primary rat anti-mouse Ly-6G antibody, 1:100 dilution; BD Pharmingen), MOMA-2 conditions (primary anti-MOMA-2 antibody, 1:200 dilution; Serotec, Raleigh, NC, USA), and secondary antibody conditions for both primary antibodies (mouse adsorbed biotinylated rabbit antirat IgG antibody, 1:50; Vector Laboratories). All antibody incubations were performed for $30 \mathrm{~min}$ at room temperature. Wound sections stained for Ly-6G or MOMA-2 were used to determine the number of neutrophils or macrophages in tissue immediately adjacent to the wound margins. The measurements were made in $100 \times$ fields.

\section{Statistical Analysis}

Data were analyzed using GraphPad Prism (GraphPad Software Inc.). Statistical differences were determined by two-way ANOVA with Bonferroni post tests or unpaired $t$-tests, with values of $P<0.05$ considered statistically significant.

\section{RESULTS}

\section{Increased Blood Vessel Density and VEGF Levels Coincide with Scarring in Fetal Wounds}

Fetal skin can heal with or without a scar, depending on the developmental age of the fetus. We determined whether differences in angiogenesis occur during the transition from scarless (E15) to fibrotic (E18) healing in fetal skin. When 

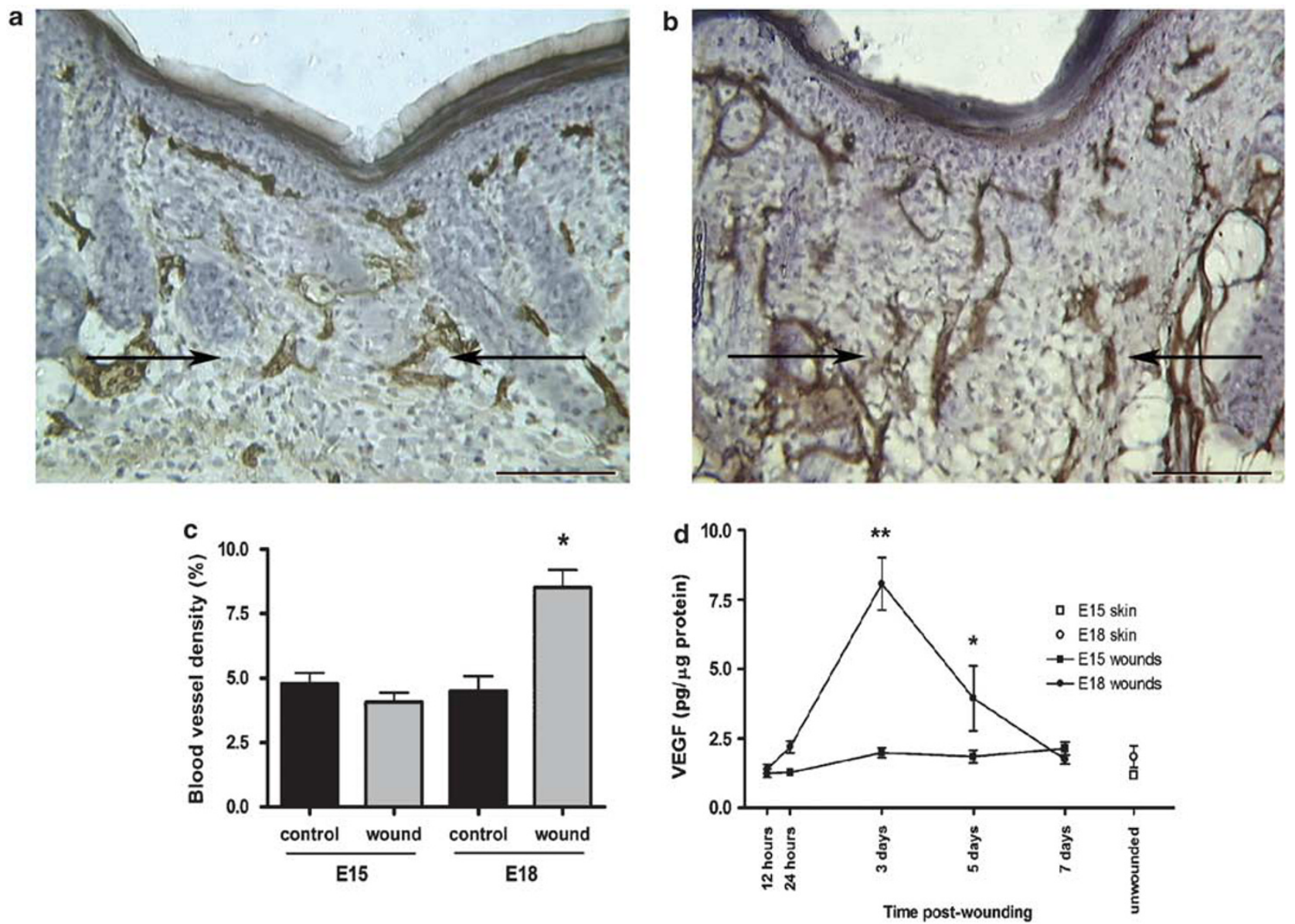

Figure 1 Blood vessel density and VEGF protein production in scarless and fibrotic fetal wounds. Immunohistochemical staining for PECAM was used to identify blood vessels in scarless (a, E15) and fibrotic (b, E18) fetal wounds 7 days post-wounding. Arrows indicate the wound bed or scar margins (scale bar $=100 \mu \mathrm{m}$ ). Blood vessel densities were calculated and are represented graphically (c). Data from day 7 wounds and unwounded, age-matched skin (control) are shown. The bars and lines represent means \pm s.e.m.; ${ }^{*} P<0.0076$, unpaired $t$-test; $n=3$ per age for control skin; $n=10$ for E15 wounds, and $n=7$ for E18 wounds. VEGF protein levels in unwounded skin and wound homogenates were measured by ELISA (d). VEGF levels in wounds made at E15 ( $\mathbf{\square})$ or E18 $(\bullet)$ were measured during healing. Unwounded E15 $(\square)$ and E18 $(\bigcirc)$ skin are also shown. The amount of VEGF (pg) was normalized to total protein content $(\mu \mathrm{g})$. Points and lines on the graph represent means \pm s.e.m.; ${ }^{* * P}<0.001$ and ${ }^{*} P<0.05$, two-way ANOVA and Bonferroni posttests; $n=3-6$ per time point.

fetuses were wounded at E15, blood vessel density was similar in wounded skin 7 days post-wounding (Figure 1a and c) and age-matched, unwounded skin (control). However, when fetuses were wounded at E18, the wounds exhibited nearly a twofold increase in vessel density compared with control skin (Figure $1 \mathrm{~b}$ and $\mathrm{c}$ ). The increased vascular density in scarforming E18 wounds suggests a link between the levels of wound angiogenesis and the amount of scar tissue formed as a result of the healing process.

Protein levels of the proangiogenic molecule VEGF were assessed by ELISA in wounds made at E15 or E18, or in unwounded skin (Figure 1d). VEGF levels in wounds generated at E15 remained at steady, low levels over the time course of healing. In contrast, wounds generated at E18 contained significantly higher levels of VEGF than those generated at E15. In wounds generated at E18, VEGF levels peaked at 3 days post-wounding with fourfold higher levels than in E15 wounds $(8.06 \pm 0.94 v s 1.99 \pm 0.18 \mathrm{pg} / \mu \mathrm{g}$ total protein), and then gradually decreased and returned to baseline by day 7 . Taken together, it is likely that the increase in vascular density during healing of E18 skin results from production of more VEGF during repair at the fibrotic healing stage.

\section{VEGF Promotes Angiogenesis and Scar Formation in Early Fetal Skin}

The production of high levels of VEGF in fibrotic (E18) fetal wounds (Figure 1) suggested that VEGF was playing a novel role in the production of scar tissue. To investigate this possibility, the effect of exogenous VEGF on scarless fetal wound healing was examined. Wounds were made at E15 and either injected with PBS as a control or with $0.1 \mu \mathrm{g}$ of rmVEGF $_{164}$ and harvested 10 days post-wounding. Analysis of blood vessel density within the wounds demonstrated the ability of this dose of VEGF to increase the level of angiogenesis, as there was a significantly higher density of blood 

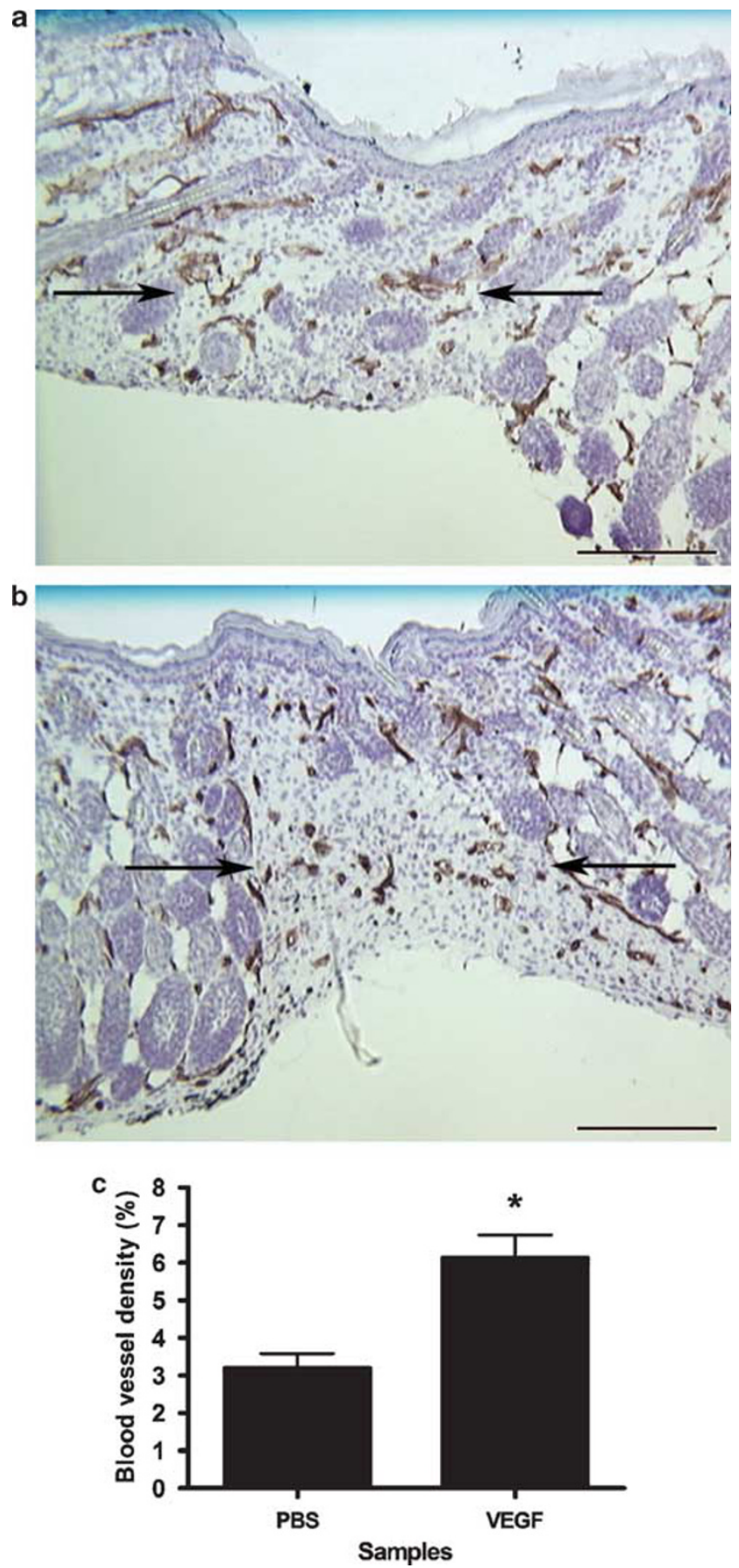

Figure 2 Effect of VEGF on fetal wound vascularity and scarring. Immunohistochemical staining for PECAM was used to identify blood vessels in wounds generated at E15 that had been injected with either PBS (a) or $0.1 \mu \mathrm{g} \mathrm{rmVEGF}_{164}$ (b), 10 days post-wounding. Arrows indicate the wound $\mathrm{bed} / \mathrm{scar}$ margins (scale bar $=200 \mu \mathrm{m}$ ). Blood vessel densities were determined and are represented graphically (c). The bars and lines represent means \pm s.e.m.; ${ }^{*} P<0.007$, unpaired $t$-test; $n=4$ for PBS and $n=5$ for VEGF.

vessels in wounds injected with VEGF (Figure $2 \mathrm{~b}$ and $\mathrm{c}$ ) compared with control wounds (Figure $2 \mathrm{a}$ and $\mathrm{c}$ ).

Wound sections were also subjected to Masson's trichrome staining and examined for presence of scar tissue. As expected, control wounds injected with PBS (Figure 3a and b) healed without a scar. In contrast, wounds injected with rmVEGF $_{164}$ healed with an obvious scar (Figure $3 \mathrm{c}$ and $\mathrm{d}$ ) indicated by loss of hair follicles and densely packed, disorganized collagen. The intensity of the trichrome stain demonstrates increased collagen content in VEGF-injected wounds. The ability of VEGF to promote scar tissue in wounds that would otherwise heal scarlessly further supports a link between VEGF, angiogenesis, and scarring.

\section{Identification of Fibroblasts and Myofibroblasts in Fetal Wounds}

The potential mechanisms for VEGF-induced scar formation in fetal wounds include an increase in fibroblast numbers or an increased presence of myofibroblasts, a cell type known to correlate with scarring in fetal wounds. Immunohistochemical staining was used to identify vimentin-positive fibroblasts and $\alpha$-SMA-positive myofibroblasts in E15 wounds injected with either PBS or rmVEGF $_{164}$ at 7 days post-wounding, and image analysis was used to determine the density of the staining. As shown in Figure 4, an increased number of vimentin-positive cells were seen in VEGF-treated wounds (Figure $4 \mathrm{~b}$ ) compared to control wounds injected with PBS (Figure 4a). Interestingly, in addition to an increase in overall vimentin-positive staining, a different pattern of expression was also noted, with vimentin staining present in the more superficial areas of the dermis in control wounds compared with staining in the deeper dermis in VEGFtreated wounds. There was also more intense staining for $\alpha$-SMA in VEGF-treated wounds (Figure 4e) compared to controls (Figure $4 \mathrm{~d}$ ). Significant increases in the percentage of vimentin- (Figure 4c) and $\alpha$-SMA-positive staining (Figure 4f) within the wound bed/scar following VEGF injection were confirmed using image analysis. Taken together, these data suggest that an increase in total fibroblast numbers and/or an increase in myofibroblast numbers could be responsible for scar tissue production after exposure to VEGF.

\section{Effects of VEGF Neutralization on Wound Vascularization and Scar Formation in Adult Skin}

To further explore the role of VEGF in dermal scarring, neutralizing VEGF antibodies were used to block VEGF activity in an adult murine incisional wound model. Before determining any effects of anti-VEGF antibody injections on the repair process, the effectiveness of the treatment regimen was verified. Injections with anti-VEGF antibodies (Figure 5b) significantly reduced the density of PECAMpositive blood vessels within the wound area 14 days post injury (Figure $5 \mathrm{c}$ ) compared with wounds from mice injected with goat IgG antibodies (Figure 5a), confirming the ability of anti-VEGF antibodies to neutralize VEGF.

The effect of anti-VEGF antibody injections on scarring was assessed by measuring the width of the scars in Masson's trichrome-stained tissue sections. Histologically, scars from 

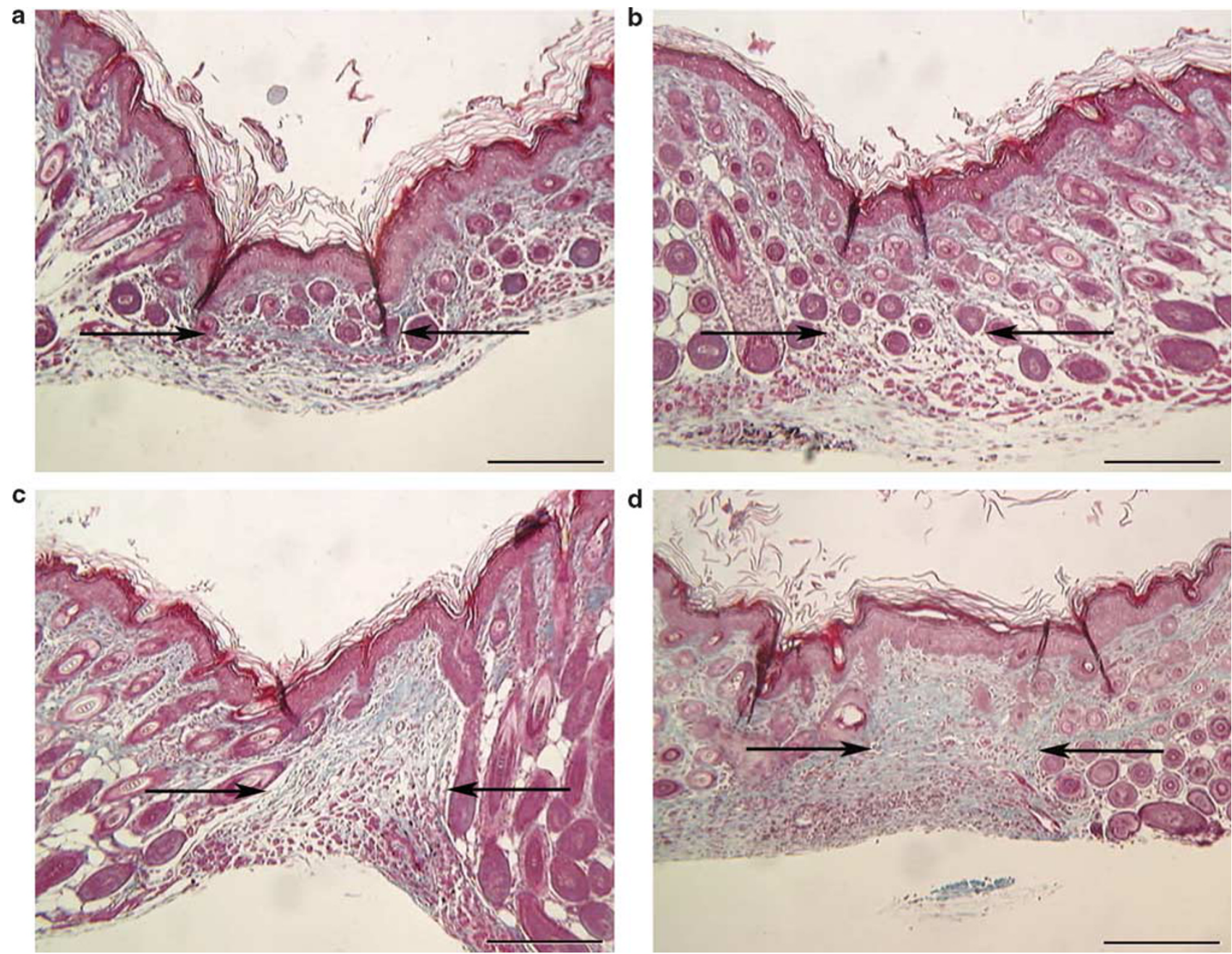

Figure 3 Effect of VEGF on fetal wound healing. Masson's trichrome staining was used to identify scar tissue in E15 fetal wounds at 10 days post-wounding. Representative trichrome-stained wound sections are shown to illustrate the lack of scarring in wounds injected PBS (a, b) and the presence of a scar in wounds injected with $0.1 \mu \mathrm{g} \mathrm{rmVEGF}_{164}$ (c, d). Arrows indicate the wound bed/scar margins (scale bar $=200 \mu \mathrm{m}$ ).

mice injected with anti-VEGF antibodies (Figure $6 \mathrm{~b}$ and $\mathrm{c}$ ) were significantly smaller in width than those from control mice injected with IgG (Figure 6a and c). Injections with anti-VEGF antibodies resulted in nearly a $75 \%$ reduction in scar width, with an average width of $48 \pm 6 \mu \mathrm{m}$, compared with control scars, which were $197 \pm 59 \mu \mathrm{m}$ in width.

\section{VEGF Blockade Influences the Organization of Scar Tissue}

In addition to the size of the scars (Figure 6), ultrastructural collagen organization was examined as an indication of the quality of the scar tissue. Using TEM, the diameter of the collagen fibrils was determined in normal unwounded skin (Figure 7a) as well as scar tissue from mice injected with IgG control (Figure 7b) and anti-VEGF (Figure 7c) antibodies. The relative frequencies within a specific range of diameters were calculated and a histogram to show the differences in the distribution of collagen fibril diameters was created (Figure 7d). As expected, unwounded skin contained relatively large collagen fibrils of a uniform size, most in the range of 41 to $80 \mathrm{~nm}$. In contrast, scar tissue from control mice injected with $\operatorname{IgG}$ antibodies contained a high frequency of very small-diameter fibrils (less than $40 \mathrm{~nm}$ ), similar to what is found in models of cutaneous fibrosis. ${ }^{20-22}$ Scars from mice injected with anti-VEGF antibodies contained a lower frequency of the small-diameter fibrils $(0-40 \mathrm{~nm})$ and a higher frequency of fibrils within the normal range (41-80 nm) compared with control scars. The results suggest that neutralization of VEGF not only reduced the amount of scar tissue formed (Figure 6), but also improved the quality of the scar tissue that did form by shifting the collagen fibril distribution to a state more closely resembling normal skin (Figure 7).

\section{Neutralization of VEGF does not Alter Acute Wound Inflammation}

Inflammation is known to play a crucial role in regulating scar tissue formation in both fetal and adult wounds. ${ }^{10,19,23-26}$ 
a

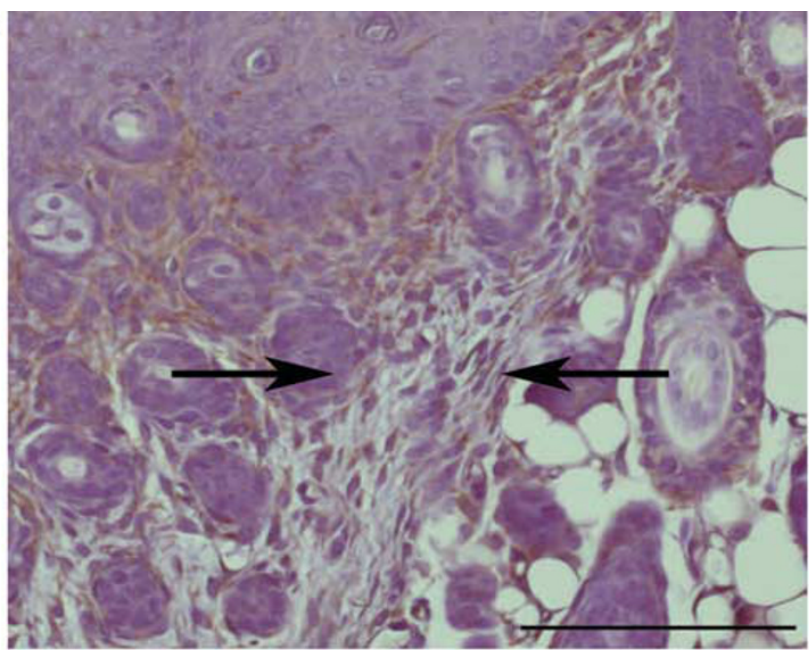

b

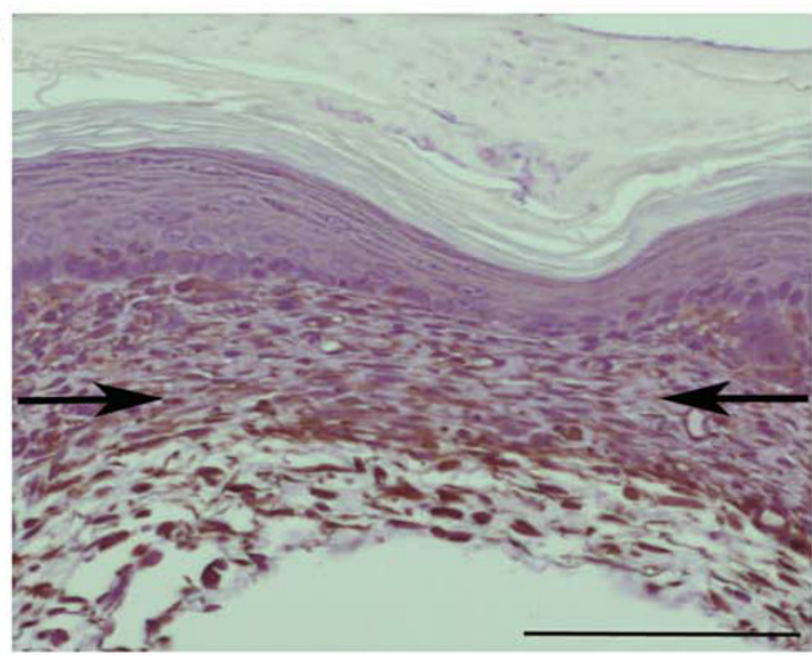

c

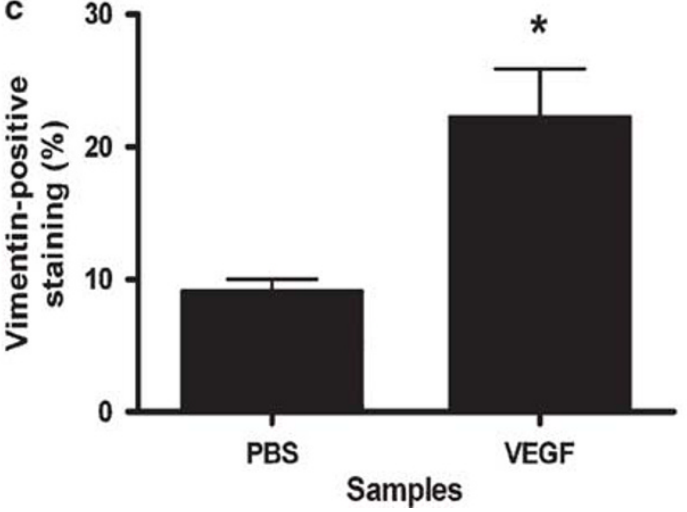

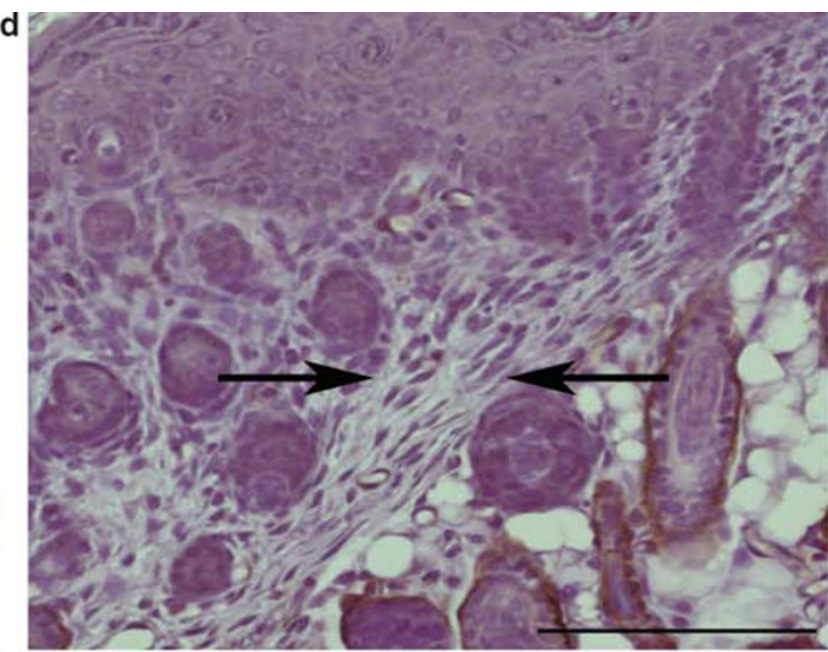

e
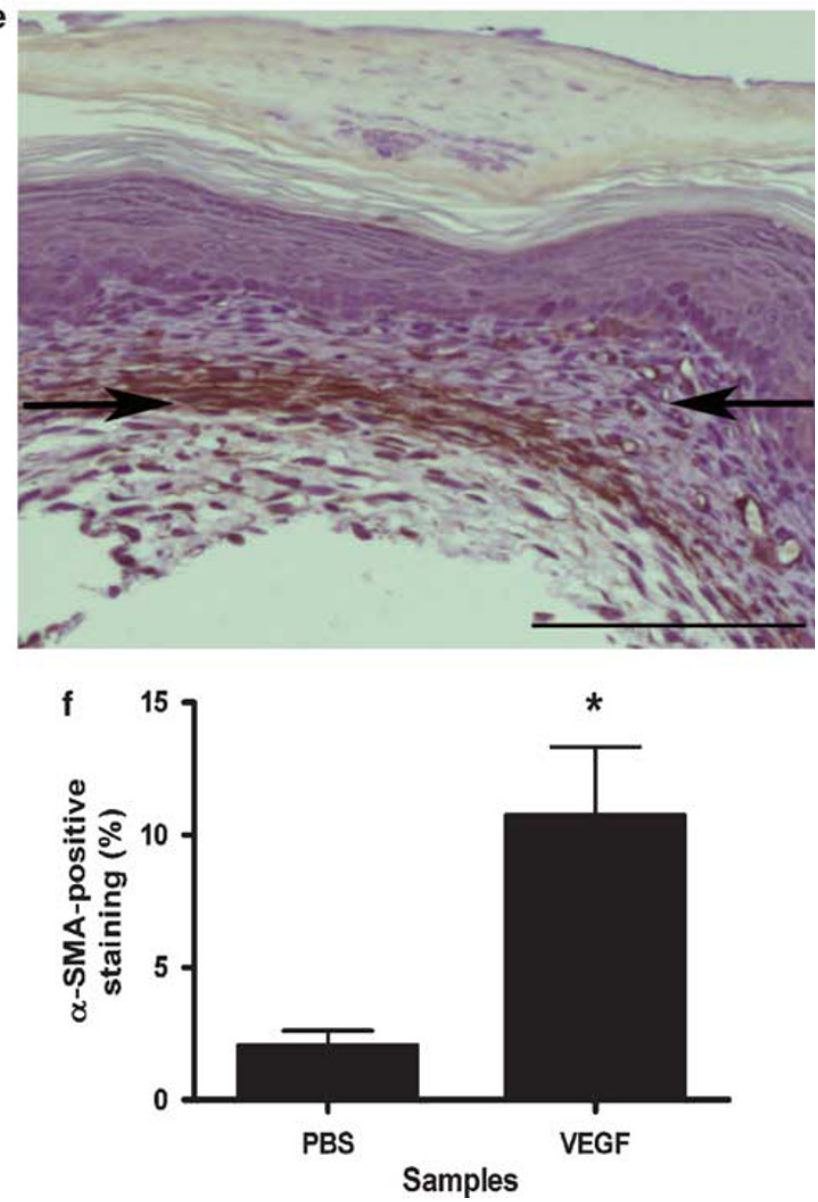

Figure 4 Enhancement of fibroblast and myofibroblast numbers in VEGF-treated fetal wounds. Immunohistochemical staining for vimentin and $\alpha$-SMA were used to detect fibroblasts and myofibroblasts, respectively, in E15 fetal wounds at 7 days post-wounding. Graphs exhibiting the density of staining as determined by image analysis and images of representative wounds are shown demonstrating an increase in both vimentin-positive fibroblasts (a-c, left panels) and $\alpha$-SMApositive myofibroblasts (d-fi, right panels) in wounds injected with $0.1 \mu \mathrm{grmVEGF}_{164}(\mathbf{b}, \mathbf{e})$ compared with control wounds injected with PBS (a, d). Arrows indicate the wound bed/scar margins (scale bar $=100 \mu \mathrm{m}$ ). The bars and lines represent means \pm s.e.m.; ${ }^{\star} P<0.01$, unpaired $t$-test; $n=5$ for PBS and $n=4$ for VEGF.

Therefore, we investigated whether the effects of VEGF blockade on scarring could be attributed to a decrease in acute inflammation with anti-VEGF antibody injections. Immunohistochemistry was used to detect neutrophils (Figure 8a) or macrophages (Figure $8 \mathrm{~b}$ ) in $24 \mathrm{~h}$ wounds, and the number of cells per high-power field (HPF) was counted. As shown in Figure 7, there were no significant differences in acute wound neutrophil or macrophage numbers between the treatment groups. 

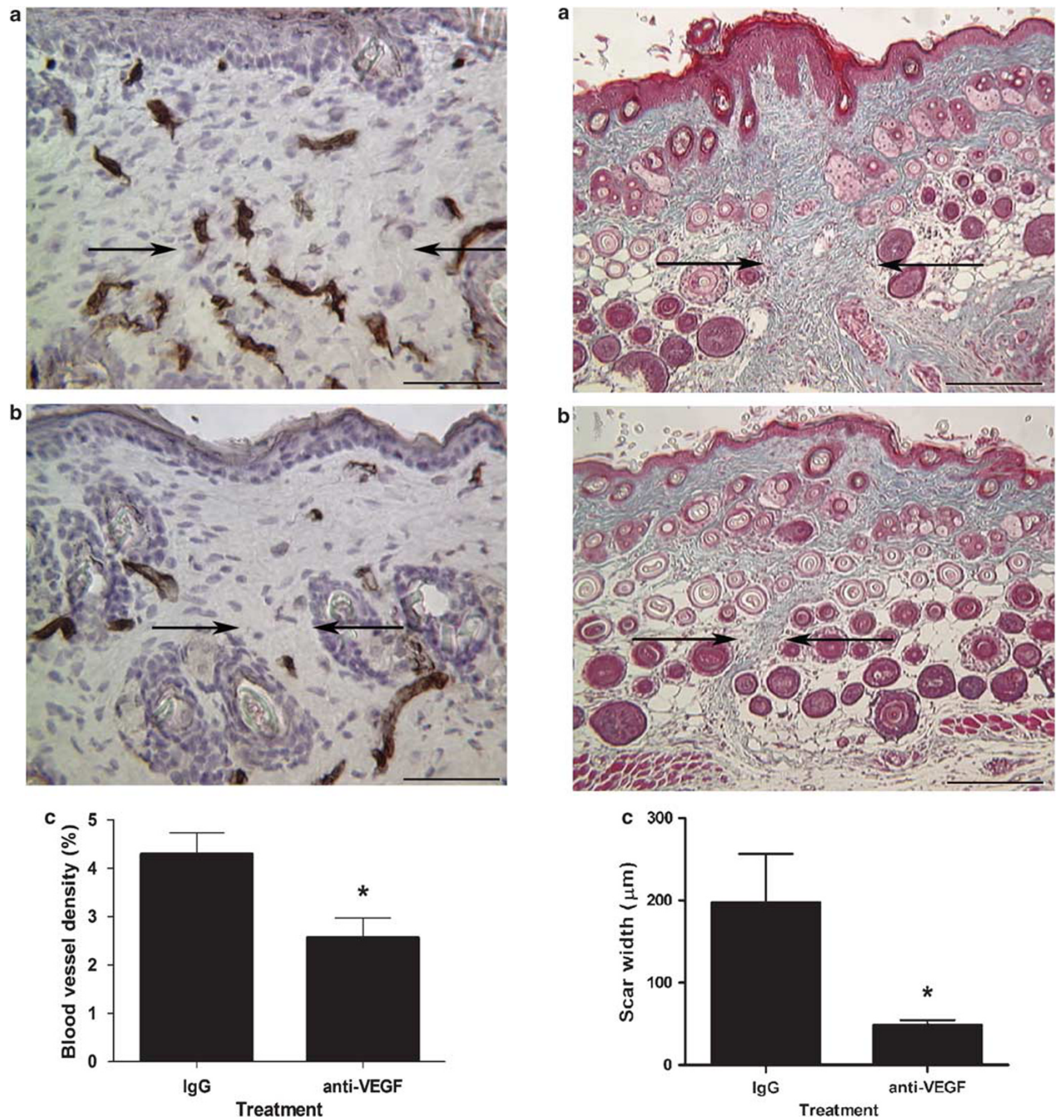

Figure 5 VEGF blockade and wound vascularity. Immunohistochemical staining for PECAM was used to identify blood vessels in wounds from mice injected with goat IgG (a) or neutralizing anti-VEGF (b) antibodies 14 days postwounding. The margins of the wound bed/scar are marked with arrows (scale bar $=100 \mu \mathrm{m}$ ). Blood vessel densities were determined and are represented graphically (c). The bars and lines represent means \pm s.e.m.; ${ }^{*} P<0.0199$, unpaired $t$-test; $n=6$ for $\lg G$ and $n=5$ for anti-VEGF for each data set.

\section{DISCUSSION}

Angiogenesis is a major component of wound repair, and in adult skin results in a peak vascular density $2-3$ times that in 

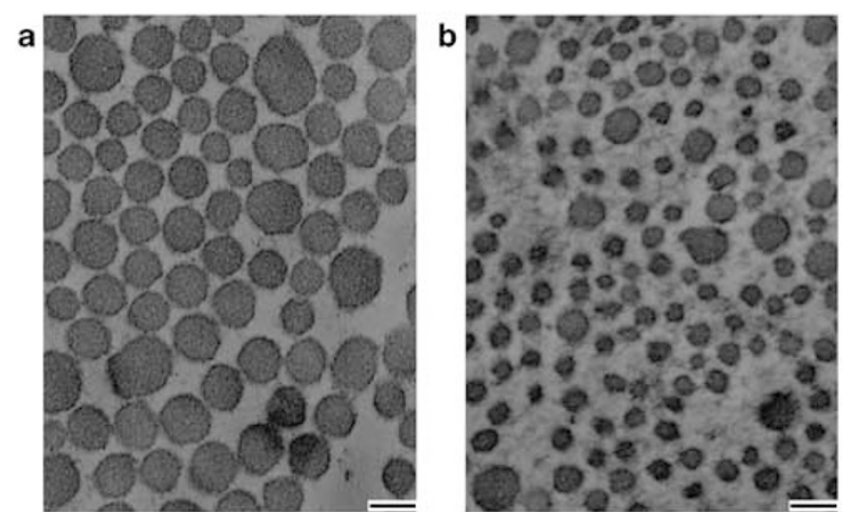

c
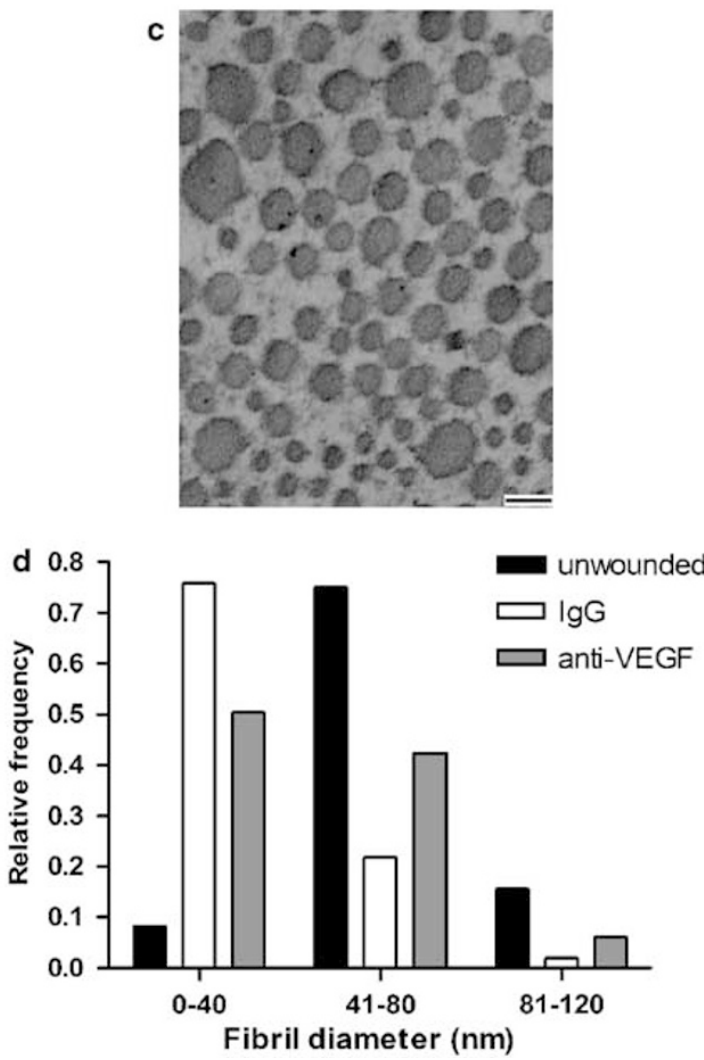

Figure 7 Ultrastructural collagen analysis. TEM was used to capture crosssectional images of collagen at a final magnification of $\times 30000$. Representative micrographs from unwounded skin (a) and 14 day scars from mice injected with goat lgG (b) or anti-VEGF antibodies (c) are shown (scale bar $=100 \mathrm{~nm}$ ). The diameters of collagen fibrils were measured using image analysis software, and a histogram of the data is shown in panel (d). The frequency of collagen fibrils within each size range $(0-40,41-80$, and $81-120 \mathrm{~nm}$ ) are shown for normal, unwounded skin, and scars from mice injected with IgG or anti-VEGF antibodies.

that many studies have found angiogenesis to be beneficial for wound repair. Stimulation of angiogenesis can enhance healing rates, ${ }^{27-33}$ whereas a reduction in angiogenesis can impair the same. ${ }^{34-37}$ The benefits of enhanced angiogenesis have primarily been shown in models of impaired wound healing ${ }^{28,32,33}$ or severe injury. ${ }^{29-31}$ In contrast, several reports have shown that modulation of angiogenesis does not
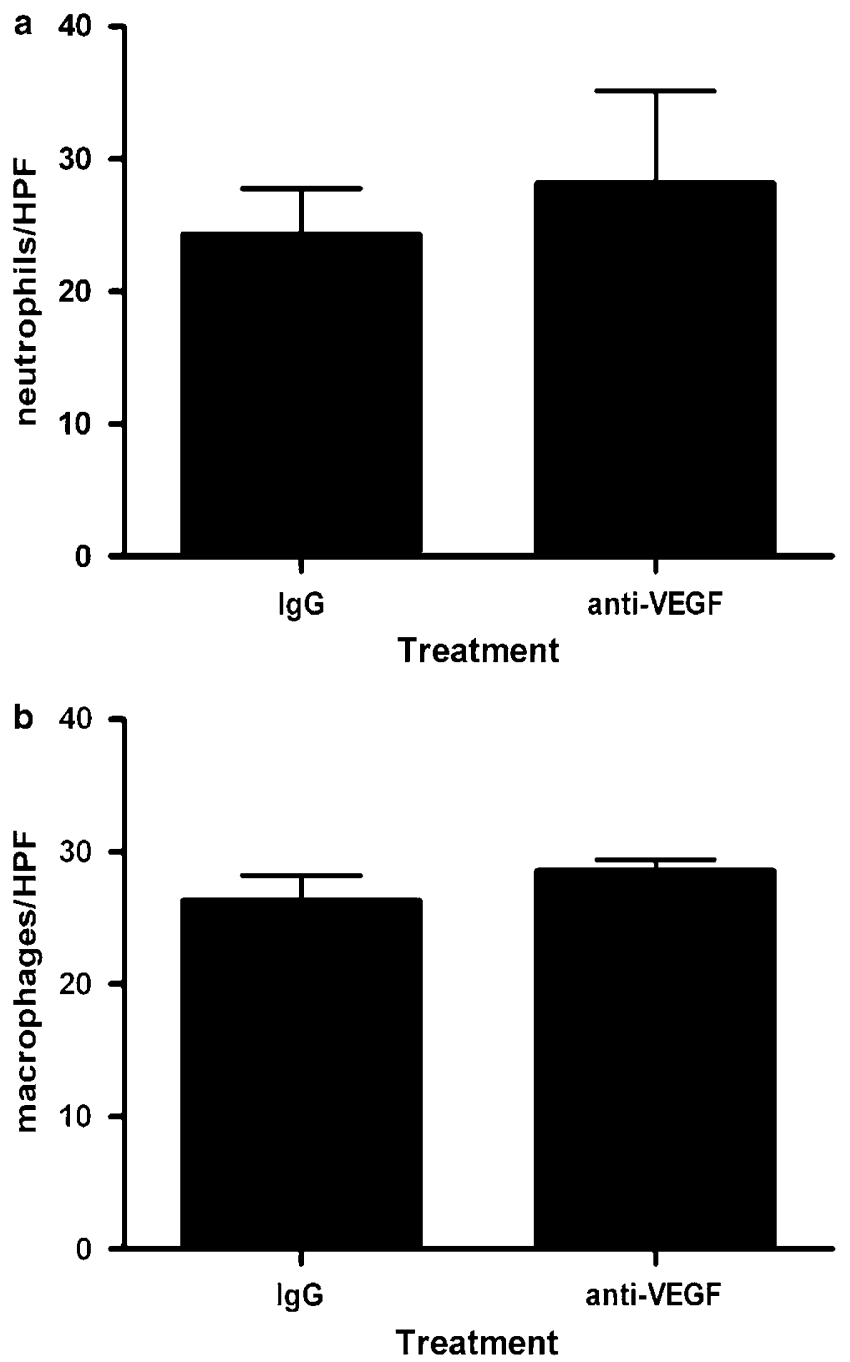

Figure 8 Effects of VEGF neutralization on acute wound inflammation. Immunohistochemistry for Ly-6G and MOMA-2 were used to identify neutrophils and macrophages in $24 \mathrm{~h}$ wounds. Neutrophil (a) and macrophage (b) numbers in tissue directly adjacent to the wound margins were counted in $100 \times$ fields. The bars and lines represent the mean number of cells per HPF \pm s.e.m.; $n=4$ per group. The results were not significant by unpaired $t$-test.

affect epidermal healing rates or overall wound closure to a great degree, ${ }^{38-43}$ and some studies have even reported enhanced healing with reduced angiogenesis. ${ }^{44}$ Thus, although there are many studies examining angiogenesis and wound repair, the degree to which angiogenesis actually facilitates healing under normal circumstances is still not known.

The effects of angiogenesis on the repair of the dermis, in particular, have been poorly studied; therefore, it is not known how angiogenesis specifically impacts collagen production and remodeling during wound repair. Our data demonstrating distinct patterns of angiogenesis and VEGF production between scarless and fibrotic fetal wounds, the ability of VEGF to promote scar tissue deposition in scarless wounds, and reduction of scar formation when VEGF is 
neutralized in adult wounds, suggest that VEGF-mediated angiogenesis plays a significant role in scar formation.

The idea that angiogenesis may affect scar formation is not entirely without precedence, as there have been a few studies suggesting that angiogenesis inhibitors can modify dermal matrix deposition. For example, endostatin treatment during wound healing has been described to alter collagen deposition, ${ }^{45}$ and CM101 has been suggested to reduce scarring in Kaposi's sarcoma patients. ${ }^{46}$ ZD6474, an inhibitor of VEGFR-2 receptor tyrosine kinase activity, has recently been reported to reduce the degree of fibrosis after wound healing. ${ }^{47}$ In fetal wounds, most studies have suggested that there are reduced levels of angiogenesis in scarless fetal wounds. ${ }^{48,49}$ In addition, fetal studies have shown that factors capable of inducing angiogenesis, such as transforming growth factor- $\beta$ (TGF- $\beta$ ), ${ }^{50}$ platelet-derived growth factor, ${ }^{51}$ basic fibroblast growth factor, ${ }^{52}$ interleukin- $8,{ }^{53}$ and prostaglandin $\mathrm{E}_{2},{ }^{54}$ are either present at lower levels during scarless healing or can induce scarring when added to these wounds. ${ }^{10,48,55-57}$ In line with these previous reports, our studies indicate that scarless fetal wounds heal without a robust increase in vascularity or VEGF levels, in contrast to fibrotic fetal wounds. Although several studies have suggested lower levels of angiogenesis in scarless fetal wounds, one recent study reported increased VEGF mRNA levels and angiogenesis in scarless compared to fibrotic fetal wounds. ${ }^{58}$ In this study, a rat model of excisional fetal wound healing was used, VEGF mRNA was assessed, blood vessels were not identified immunohistochemically, and early time points were examined. In the studies presented here, a mouse model of incisional fetal wound healing was used, VEGF protein levels were assessed, PECAM-positive vessels were analyzed, and a wider range of time points were examined. It is likely that differences in the model systems, methods, and time points examined account for the variability in results between these two studies.

Our results, using three independent systems, show that VEGF levels influence the amount of scar tissue that will be produced during the wound repair process. There are several possible mechanisms by which VEGF could promote scar tissue deposition. Inflammation is known to influence the amount of scar tissue that will be generated during the repair process. This has been shown both in fetal and adult wound-healing systems. ${ }^{10,19,25,26,57,59-62}$ Due to the ability of VEGF to promote inflammatory cell recruitment ${ }^{63,64}$ and vascular permeability, ${ }^{12}$ it seemed possible that the reduction in scar formation seen after treatment with anti-VEGF antibodies might, therefore, be a result of reduced inflammation. However, we saw no differences in acute inflammation with anti-VEGF antibody treatment, suggesting that the reduction in scarring is not completely a result of reduced inflammation.

Second, VEGF could encourage scar tissue deposition indirectly by virtue of its effects on angiogenesis, if the process of angiogenesis itself promotes scar tissue production. For example, it is possible that while undergoing angiogenesis, dermal endothelial cells could generate significant amounts of TGF- $\beta$, connective tissue growth factor, or other profibrotic factors, stimulating subsequent scar tissue production by neighboring fibroblasts. Alternatively, the matrix remodeling that accompanies angiogenesis could indirectly stimulate the production of scar tissue.

Finally, it is possible that VEGF itself could be acting as the link between angiogenesis and scar formation, by directly stimulating both endothelial cells and dermal fibroblasts. Our fetal wound healing studies showed an increase in both total fibroblast numbers as well as $\alpha$-SMA-positive myofibroblasts in VEGF-treated wounds that formed scars, suggesting VEGF may affect fibroblasts. Wu et al ${ }^{65}$ recently demonstrated the ability of VEGF to induce proliferation of keloid fibroblasts and suggest the presence of functional VEGF receptors on fibroblasts. The presence of VEGF receptors on fibroblasts is also supported by a study demonstrating expression of VEGFR-2 in stromal cells during wound repair in vivo. ${ }^{66}$ Unpublished data from our laboratory also indicate VEGFR expression in dermal fibroblasts, and studies are underway to confirm the presence of functional VEGF receptors on dermal fibroblasts and to determine whether VEGF can influence scar formation directly via signaling in fibroblasts.

Together, our results strengthen the link between angiogenesis and scarring, and suggest a novel role for VEGF in mediating the quantity and quality of scar tissue generated during wound repair. Our results are supported by reports indicating that increased VEGF levels are important for development of fibrosis in other models, including bleomycininduced lung fibrosis ${ }^{67}$ as well as liver fibrosis. ${ }^{68,69}$ High levels of VEGF have also been described in keloids in the skin. ${ }^{70,71}$ Further studies will have to be conducted to assess potential clinical uses for VEGF neutralization in limiting scar formation or managing more severe fibrotic diseases.

1. Martin P. Wound healing-aiming for perfect skin regeneration. Science 1997;276:75-81.

2. Singer AJ, Clark RA. Cutaneous wound healing. N Engl J Med 1999; 341:738-746.

3. Tredget EE, Nedelec B, Scott PG, et al. Hypertrophic scars, keloids, and contractures. The cellular and molecular basis for therapy. Surg Clin North Am 1997;77:701-730.

4. Ross RB. Treatment variables affecting facial growth in complete unilateral cleft lip and palate. Cleft Palate J 1987;24:5-77.

5. Rowlatt U. Intrauterine wound healing in a 20 week human fetus. Virchows Arch A Pathol Anat Histol 1979;381:353-361.

6. Colwell AS, Longaker MT, Lorenz HP. Fetal wound healing. Front Biosci 2003;8:s1240-s1248.

7. Cowin AJ, Brosnan MP, Holmes TM, et al. Endogenous inflammatory response to dermal wound healing in the fetal and adult mouse. Dev Dyn 1998;212:385-393.

8. Whitby DJ, Ferguson MW. The extracellular matrix of lip wounds in fetal, neonatal and adult mice. Development 1991;112:651-668.

9. Stelnicki EJ, Bullard KM, Harrison MR, et al. A new in vivo model for the study of fetal wound healing. Ann Plast Surg 1997;39:374-380.

10. Wilgus TA, Bergdall VK, Tober KL, et al. The impact of cyclooxygenase-2 mediated inflammation on scarless fetal wound healing. Am J Pathol 2004;165:753-761.

11. Nissen NN, Polverini PJ, Koch $A E$, et al. Vascular endothelial growth factor mediates angiogenic activity during the proliferative phase of wound healing. Am J Pathol 1998;152:1445-1452. 
12. Senger DR, Galli SJ, Dvorak AM, et al. Tumor cells secrete a vascular permeability factor that promotes accumulation of ascites fluid. Science 1983;219:983-985.

13. Leung DW, Cachianes G, Kuang WJ, et al. Vascular endothelial growth factor is a secreted angiogenic mitogen. Science 1989;246:1306-1309.

14. Connolly DT, Heuvelman DM, Nelson R, et al. Tumor vascular permeability factor stimulates endothelial cell growth and angiogenesis. J Clin Invest 1989;84:1470-1478.

15. Ferrara N, Gerber HP, LeCouter J. The biology of VEGF and its receptors. Nat Med 2003;9:669-676.

16. Brown LF, Yeo KT, Berse B, et al. Expression of vascular permeability factor (vascular endothelial growth factor) by epidermal keratinocytes during wound healing. J Exp Med 1992;176:1375-1379.

17. Yano K, Brown LF, Detmar M. Control of hair growth and follicle size by VEGF-mediated angiogenesis. J Clin Invest 2001;107:409-417.

18. Swift ME, Kleinman HK, DiPietro LA. Impaired wound repair and delayed angiogenesis in aged mice. Lab Invest 1999;79:1479-1487.

19. Wilgus TA, Vodovotz Y, Vittadini E, et al. Reduction of scar formation in full-thickness wounds with topical celecoxib treatment. Wound Repair Regen 2003;11:25-34.

20. Brinckmann J, Notbohm H, Tronnier M, et al. Overhydroxylation of lysyl residues is the initial step for altered collagen cross-links and fibril architecture in fibrotic skin. J Invest Dermatol 1999;113:617-621.

21. Lakos G, Takagawa S, Chen SJ, et al. Targeted disruption of TGF-beta/ Smad3 signaling modulates skin fibrosis in a mouse model of scleroderma. Am J Pathol 2004;165:203-217.

22. Ferreira AM, Takagawa S, Fresco R, et al. Diminished induction of skin fibrosis in mice with MCP-1 deficiency. J Invest Dermatol 2006;126: 1900-1908.

23. Morykwas MJ, Ditesheim JA, Ledbetter MS, et al. Monodelphis domesticus: a model for early developmental wound healing. Ann Plast Surg 1991;27:327-331.

24. Krummel TM, Nelson JM, Diegelmann RF, et al. Fetal response to injury in the rabbit. J Pediatr Surg 1987;22:640-644.

25. Kumta S, Ritz M, Hurley JV, et al. Acute inflammation in foetal and adult sheep: the response to subcutaneous injection of turpentine and carrageenan. Br J Plast Surg 1994;47:360-368.

26. Martin P, D'Souza D, Martin J, et al. Wound healing in the PU.1 null mouse-tissue repair is not dependent on inflammatory cells. Curr Biol 2003;13:1122-1128.

27. Deodato $B$, Arsic N, Zentilin $L$, et al. Recombinant $A A V$ vector encoding human VEGF165 enhances wound healing. Gene Ther 2002;9:777-785.

28. Galiano RD, Tepper OM, Pelo CR, et al. Topical vascular endothelial growth factor accelerates diabetic wound healing through increased angiogenesis and by mobilizing and recruiting bone marrow-derived cells. Am J Pathol 2004;164:1935-1947.

29. Liu PY, Tong W, Liu K, et al. Liposome-mediated transfer of vascular endothelial growth factor CDNA augments survival of random-pattern skin flaps in the rat. Wound Repair Regen 2004;12:80-85.

30. Giunta RE, Holzbach T, Taskov C, et al. AdVEGF165 gene transfer increases survival in overdimensioned skin flaps. J Gene Med 2005;7:297-306

31. Taub PJ, Marmur JD, Zhang WX, et al. Locally administered vascular endothelial growth factor CDNA increases survival of ischemic experimental skin flaps. Plast Reconstr Surg 1998;102:2033-2039.

32. Galeano $M$, Deodato $B$, Altavilla $D$, et al. Adeno-associated viral vectormediated human vascular endothelial growth factor gene transfer stimulates angiogenesis and wound healing in the genetically diabetic mouse. Diabetologia 2003;46:546-555.

33. Romano Di Peppe S, Mangoni A, Zambruno G, et al. Adenovirusmediated VEGF(165) gene transfer enhances wound healing by promoting angiogenesis in CD1 diabetic mice. Gene Ther 2002;9: $1271-1277$.

34. Takeda $\mathrm{H}$, Katagata $\mathrm{Y}$, Hozumi $\mathrm{Y}$, et al. Effects of angiotensin II receptor signaling during skin wound healing. Am J Pathol 2004;165: 1653-1662.

35. Rossiter $\mathrm{H}$, Barresi $\mathrm{C}$, Pammer J, et al. Loss of vascular endothelial growth factor a activity in murine epidermal keratinocytes delays wound healing and inhibits tumor formation. Cancer Res 2004;64:3508-3516.

36. Mori R, Kondo T, Nishie $T$, et al. Impairment of skin wound healing in beta-1, 4-galactosyltransferase-deficient mice with reduced leukocyte recruitment. Am J Pathol 2004;164:1303-1314.
37. Ekstrand $A J$, Cao $R$, Bjorndahl $M$, et al. Deletion of neuropeptide $Y$ (NPY) 2 receptor in mice results in blockage of NPY-induced angiogenesis and delayed wound healing. Proc Natl Acad Sci USA 2003;100:6033-6038.

38. Jang YC, Arumugam $\mathrm{S}$, Gibran NS, et al. Role of alpha(v) integrins and angiogenesis during wound repair. Wound Repair Regen 1999;7:375-380.

39. Jacobi J, Tam BY, Sundram U, et al. Discordant effects of a soluble VEGF receptor on wound healing and angiogenesis. Gene Ther 2004;11:302-309.

40. Hong YK, Lange-Asschenfeldt B, Velasco $P$, et al. VEGF-A promotes tissue repair-associated lymphatic vessel formation via VEGFR-2 and the alpha1beta1 and alpha2beta1 integrins. FASEB J 2004;18: 1111-1113.

41. Vranckx JJ, Yao F, Petrie N, et al. In vivo gene delivery of Ad-VEGF121 to full-thickness wounds in aged pigs results in high levels of VEGF expression but not in accelerated healing. Wound Repair Regen 2005;13:51-60.

42. Lange-Asschenfeldt B, Velasco P, Streit M, et al. The angiogenesis inhibitor vasostatin does not impair wound healing at tumorinhibiting doses. J Invest Dermatol 2001;117:1036-1041.

43. Roman CD, Choy H, Nanney L, et al. Vascular endothelial growth factormediated angiogenesis inhibition and postoperative wound healing in rats. J Surg Res 2002;105:43-47.

44. Nanney LB, Wamil BD, Whitsitt J, et al. CM101 stimulates cutaneous wound healing through an anti-angiogenic mechanism. Angiogenesis 2001;4:61-70.

45. Bloch W, Huggel K, Sasaki T, et al. The angiogenesis inhibitor endostatin impairs blood vessel maturation during wound healing. FASEB J 2000;14:2373-2376.

46. DeVore RF, Hellerqvist CG, Wakefield GB, et al. Phase I study of the antineovascularization drug CM101. Clinical Can Res 1997;3:365-372.

47. Ko J, Ross J, Awad H, et al. The effects of ZD6474, an inhibitor of VEGF signaling, on cutaneous wound healing in mice. J Surg Res 2005;129:251-259.

48. Whitby DJ, Ferguson MW. Immunohistochemical localization of growth factors in fetal wound healing. Dev Biol 1991;147:207-215.

49. Ihara $S$, Motobayashi $Y$, Nagao $E$, et al. Ontogenetic transition of wound healing pattern in rat skin occurring at the fetal stage. Development 1990;110:671-680.

50. Roberts AB, Sporn MB, Assoian RK, et al. Transforming growth factor type beta: rapid induction of fibrosis and angiogenesis in vivo and stimulation of collagen formation in vitro. Proc Natl Acad Sci USA 1986;83:4167-4171.

51. Ishikawa F, Miyazono K, Hellman U, et al. Identification of angiogenic activity and the cloning and expression of platelet-derived endothelial cell growth factor. Nature 1989;338:557-562.

52. Montesano R, Vassalli JD, Baird A, et al. Basic fibroblast growth factor induces angiogenesis in vitro. Proc Natl Acad Sci USA 1986;83:7297-7301.

53. Koch $A E$, Polverini PJ, Kunkel $S L$, et al. Interleukin-8 as a macrophagederived mediator of angiogenesis. Science 1992;258:1798-1801.

54. Form DM, Auerbach R. PGE2 and angiogenesis. Proc Soc Exp Biol Med 1983;172:214-218.

55. Krummel TM, Michna BA, Thomas BL, et al. Transforming growth factor beta (TGF-beta) induces fibrosis in a fetal wound model. J Pediatr Surg 1988;23:647-652.

56. Haynes JH, Johnson DE, Mast BA, et al. Platelet-derived growth factor induces fetal wound fibrosis. J Pediatr Surg 1994;29:1405-1408.

57. Liechty KW, Crombleholme TM, Cass DL, et al. Diminished interleukin-8 (IL-8) production in the fetal wound healing response. J Surg Res 1998;77:80-84.

58. Colwell AS, Beanes SR, Soo C, et al. Increased angiogenesis and expression of vascular endothelial growth factor during scarless repair. Plast Reconstr Surg 2005;115:204-212.

59. Armstrong JR, Ferguson MW. Ontogeny of the skin and the transition from scar-free to scarring phenotype during wound healing in the pouch young of a marsupial, Monodelphis domestica. Dev Biol 1995; 169:242-260.

60. Frantz FW, Bettinger DA, Haynes JH, et al. Biology of fetal repair: the presence of bacteria in fetal wounds induces an adult-like healing response. J Pediatr Surg 1993;28:428-433, discussion 433-424.

61. Liechty KW, Adzick NS, Crombleholme TM. Diminished interleukin 6 (IL-6) production during scarless human fetal wound repair. Cytokine 2000;12:671-676. 
62. Liechty KW, Kim HB, Adzick NS, et al. Fetal wound repair results in scar formation in interleukin-10-deficient mice in a syngeneic murine model of scarless fetal wound repair. J Pediatr Surg 2000;35:866-872, discussion 872-863.

63. Ancelin M, Chollet-Martin S, Herve MA, et al. Vascular endothelial growth factor VEGF189 induces human neutrophil chemotaxis in extravascular tissue via an autocrine amplification mechanism. Lab Invest 2004;84:502-512.

64. Barleon B, Sozzani S, Zhou D, et al. Migration of human monocytes in response to vascular endothelial growth factor (VEGF) is mediated via the VEGF receptor flt-1. Blood 1996;87:3336-3343.

65. Wu WS, Wang FS, Yang KD, et al. Dexamethasone induction of keloid regression through effective suppression of VEGF expression and keloid fibroblast proliferation. J Invest Dermatol 2006;126:1264-1271.

66. Zhang N, Fang Z, Contag PR, et al. Tracking angiogenesis induced by skin wounding and contact hypersensitivity using a Vegfr2-luciferase transgenic mouse. Blood 2004;103:617-626.
67. Fehrenbach $\mathrm{H}$, Haase $\mathrm{M}$, Kasper $\mathrm{M}$, et al. Alterations in the immunohistochemical distribution patterns of vascular endothelial growth factor receptors Flk1 and Flt1 in bleomycin-induced rat lung fibrosis. Virchows Arch 1999;435:20-31.

68. Corpechot C, Barbu V, Wendum D, et al. Hypoxia-induced VEGF and collagen I expressions are associated with angiogenesis and fibrogenesis in experimental cirrhosis. Hepatology 2002;35:1010-1021.

69. Yoshiji H, Kuriyama S, Yoshii J, et al. Vascular endothelial growth factor and receptor interaction is a prerequisite for murine hepatic fibrogenesis. Gut 2003;52:1347-1354.

70. Wu Y, Zhang Q, Ann DK, et al. Increased vascular endothelial growth factor may account for elevated level of plasminogen activator inhibitor-1 via activating ERK1/2 in keloid fibroblasts. Am J Physiol Cell Physiol 2004;286:C905-C912.

71. Gira AK, Brown LF, Washington CV, et al. Keloids demonstrate high-level epidermal expression of vascular endothelial growth factor. J Am Acad Dermatol 2004;50:850-853. 